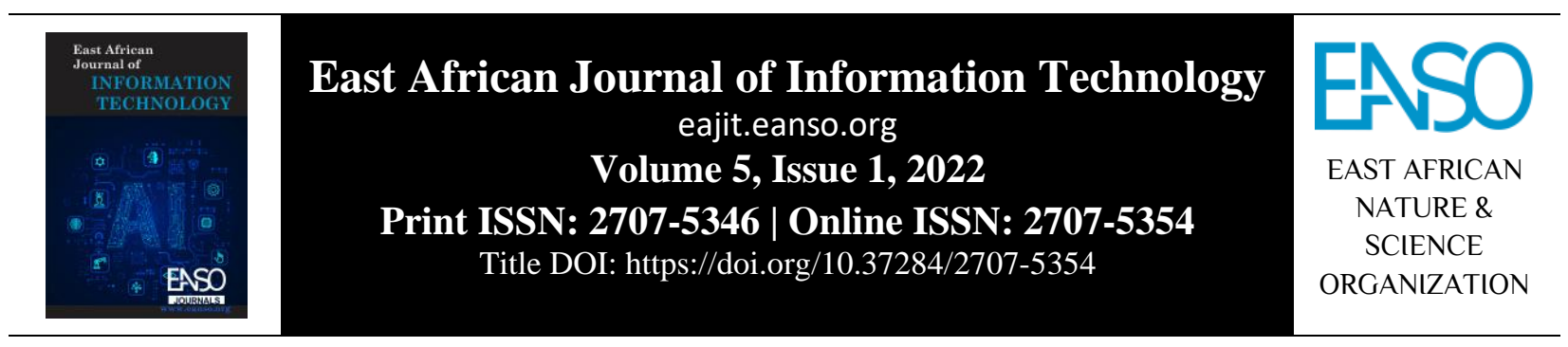

Original Article

\title{
Technical, Usability, Content and Other factors (TUCO) Framework for website upgrade in Higher Education Institution.
}

\author{
Dr. Caroline Chepkoech Kiptoo, $P h D^{l}$ \\ ${ }^{1}$ University of Nairobi, P.O. Box 30197, GPO, Nairobi, Kenya. \\ * Correspondence ORCID ID: https://orcid.org/0000-0002-1140-0697; email: cckiptoo@uonbi.ac.ke.
}

Article DOI: https://doi.org/10.37284/eajit.5.1.553

\section{Date Published: ABSTRACT}

16 February 2022 This paper presents a framework for the upgrade of Higher Education Institutions (HEI) websites. The objectives of the research are to examine

Keywords: important factors for Higher Education Institutions (HEI) websites upgrade and develop a framework and guidelines for the upgrade of websites of

Website Upgrade, HEI Website, Website Guidelines these institutions. The framework is anchored on the requirement of any upgrade to guarantee continuity in two important roles of a HEI website, namely; the continuity of the institutional image, and the continuity of online service delivery to stakeholders. The research adopted the Design Science Research (DSR) approach which is a problem-solving paradigm and considers research as capable of bringing change through introduction of novel artefacts that address societal challenges. DSR is characterised by two major iterative cycles of build and evaluate activities that are executed until a sufficient artefact is realised. The framework was developed during the conclusion phase of the research. The Framework is named TUCO, representing the initials of the framework lenses of Technical, Usability, Content and Other factors. The lenses are connected by a hinge that holds together all the lenses and represents the flexibility of the framework which allows for an upgrade to be done by looking through at one lens or a combination of different lenses depending on the priorities of the upgrade and the resources available. Each lens has a number of components that must be considered during an upgrade. The framework contributes to the HEI websites body of knowledge and provides support and practical guideline for practitioners. 
East African Journal of Information Technology, Volume 5, Issue 1, 2022

Article DOI: https://doi.org/10.37284/eajit.5.1.553

\section{APA CITATION}

Kiptoo, C. C. (2022). Technical, Usability, Content and Other factors (TUCO) Framework for website upgrade in Higher Education Institution. East African Journal of Information Technology, 5(1), 7-19. https://doi.org/10.37284/eajit.5.1.553

\section{CHICAGO CITATION}

Kiptoo, Caroline Chepkoech. 2022. "Technical, Usability, Content and Other factors (TUCO) Framework for website upgrade in Higher Education Institution”. East African Journal of Information Technology 5 (1), 7-19. https://doi.org/10.37284/eajit.5.1.553.

\section{HARVARD CITATION}

Kiptoo, C. C. (2022) "Technical, Usability, Content and Other factors (TUCO) Framework for website upgrade in Higher Education Institution”, East African Journal of Information Technology, 5(1), pp. 7-19. doi: 10.37284/eajit.5.1.553.

\section{IEEE CITATION}

C. C., Kiptoo. "Technical, Usability, Content and Other factors (TUCO) Framework for website upgrade in Higher Education Institution", EAJIT, vol. 5, no. 1, pp. 7-19, Feb. 2022.

\section{MLA CITATION}

Kiptoo, Caroline Chepkoech. "Technical, Usability, Content and Other factors (TUCO) Framework for website upgrade in Higher Education Institution". East African Journal of Education Studies, Vol. 5, no. 1, Feb. 2022, pp. 7-19, doi:10.37284/eajit.5.1.553.

\section{INTRODUCTION}

The web phenomenon has changed how people work and Higher Education Institutions (HEIs) are no exception. Websites have become a strategic tool in HEIs and it is safe to say that all universities worldwide have websites. A random check of renowned universities indicate that many domain names were registered from the mid 1980's to early 2000s. For example, a random check using who is net indicated that University of Oxford in the United Kingdom,oxford.ac.uk, was registered on or before 1996; Harvard University in the USA, harvard.edu was registered in 1986; Massachusetts Institute of Technology (MIT) in the USA, mit.edu, was registered in 1986; University of Cambridge in the United Kingdom, cam.ac.uk, was registered on or before 1996; Makerere University in Uganda, mak.ac.ug, was registered in 2001; University of Ibadan in Nigeria, ui.edu.ng, was registered in 2009; and the University of Nairobi in Kenya which is the case used in this research was registered in 2003. This indicates that majority of the institutions have had their website for over 20 years and therefore the websites must have undergone some upgrade(s) at some stage.

In the former years, institutions used the websites as an information dissemination tool based on an information broadcasting model. Website upgrades in this period therefore entailed ensuring optimal website hosting technology and logical organization of content for broadcasting to the public. More recently, advancement in web technologies has made it possible to not only broadcast, but to engage a wide range of stakeholders through the websites. This has been made possible through the emergence of technologies such as Web 2.0 and the social web (Armstrong \& Franklin, 2008; Conole and Alevizou, 2010; Hollinderbäumer et al., 2013; Paul, 2013). These technological advances combined with the mainstreaming of websites as a strategic tool for stakeholders engagement make upgrade of institutional website an exercise that must be undertaken with multiple considerations.

\section{Research Question}

A search in HEI websites literature indicates that research efforts have been put into design of the websites, usability, evaluation of the websites using different frameworks, website metrics and web accessibility. Research on website upgrades is scanty and this research seeks to fill this gap by taking into account several factors that must be considered during an upgrade. The research sought to answer the question:

What are the factors that must be considered during a HEI website upgrade in order to guarantee continuity of the institution's image, stakeholder engagement and service delivery?

In answering this question, the research proposes a framework for HEI websites upgrade with key motivation being to ensure continuity of services 
and stakeholder engagement; as well as sustenance of the institution's image (virtual and real) that has been built over time.

\section{LITERATURE REVIEW}

As stated in the introduction, websites have become strategic tools in HEIs. Research on websites have also been conducted focusing on different aspects of HEI websites. In general, the studies have considered audience classes, usability, design issues, content types, web metrics, web accessibility and surveys looking at different aspects of the websites. On HEI website audience, different categories of users are identified in Pierce (2005), as consisting of prospective students, parents, prospective faculty and staff, donors and alumni. Other studies consider expectations / motivations of specific audience categories on the HEI websites, for instance in Al-Debei (2014), the behavioural factors that influence students to regularly use university websites are studied.

On usability, several studies have been carried out consisting of evaluation surveys, usability guidelines and frameworks among others. In Caglar and Mentes (2012), an evaluation of the usability of the European University of Lefke website is presented. Chow et al. (2014) carried out a survey of academic and public libraries websites in the USA, evaluating their design and usability. Another example of usability study on HEI website is that of Mentes and Turan (2012), where they measured the usability of the Namık Kemal University (NKU) web site based on five selected factors of usability: attractiveness, controllability, helpfulness, efficiency and learnability.

Content hosted in HEI website have similarities across institutions. Different researchers have interrogated content hosted in HEI websites and the website contents are classified using some logical groupings. The common contents types include static information, dynamic information, student information, research information, staff information, visitor information, news, announcements, notices, courseware, publications, journals and calendars (Bernier et al., 2002; Mohammed et al., 2014)
Website metrics have become important parameters for developing criteria of measuring the quality of HEI institutions. Research on website metrics have been contacted both at global levels, country levels and even at institutional level. The objectives of most research on web metrics can be broadly categorized into those seeking to identify relevant web metrics and incorporate into ranking criteria and those seeking to evaluate performances. The web metrics have gained significance in shaping public perceptions on the quality of HEIs. As a result, many HEIs have from time-to-time developed strategies to achieve a competitive ranking on the web. An example of rankings that target HEIs is the webometrics ranking (Aguillo et al., 2008, 2010).

More recently, research on website accessibility is emerging with studies focussing on evaluation of HEI websites compliance to web accessibility standards. An example of research in this category is Akgul (2017), which measures universal accessibility of Jordan universities using the WCAG 1.0 standard, identifies the most violated guidelines and goes ahead to make recommendations for better compliance. Other examples include an evaluation of top ranking university in Oceania on their web (Home, Admission, and Course Description Webpages) accessibility to students with disabilities (Alahmadi and Drew, 2017); and a systematic literature review on web accessibility of Saudi Arabian universities and government websites to persons with disability (Akram and Sulaiman, 2017).

Although a lot of research has been done on HEIs websites, our literature search did not reveal any studies focused on frameworks or guidelines for HEIs website upgrades. The literature reviewed and summarised above allude to important factors whether designing a new website or upgrading, but they are not focused specifically on upgrades with continuity as a goal. As pointed out in the introduction, the role of HEI websites includes information sharing, stakeholder engagement through dialogue, and projection of a positive image. Any website upgrades should therefore consider continuity of these important roles of an institutional website. This research seeks to fill this gap by providing a framework and guidelines for HEI website upgrade.

9| This work is licensed under a Creative Commons Attribution 4.0 International License. 


\section{RESEARCH METHODOLOGY}

\section{Research Approach}

This research adopted the Design Science Research (DSR) approach which is premised in the pragmatic world view which view the world as capable of change through introduction of interventions. DSR is a problem-solving paradigm and research is positioned in the centre of a practical problem and theory. DSR is therefore characterised by three cycles, namely: the design cycle, supported by two sets of activities in the rigour and relevance cycles as shown in Figure 1.

Figure 1: Design Science Research Cycles

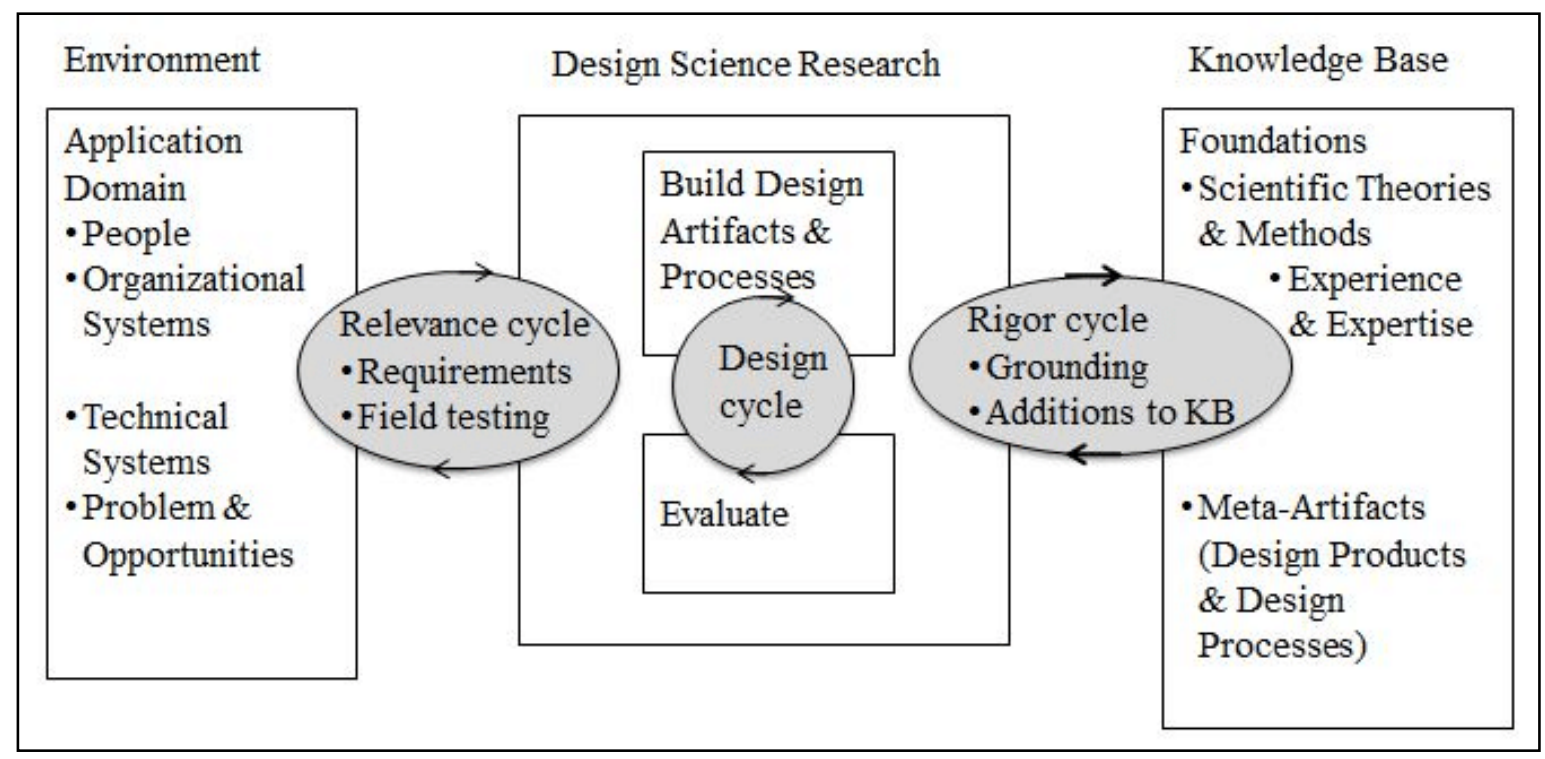

Source: (Hevner, 2007)

\section{Research Process}

Different processes have been proposed for carrying out research in DSR. This research adopted the process presented in Vaishnavi and Kuechler (2007), consisting of five circumscriptive steps of awareness of problem, suggestion, development, evaluation and conclusion as shown in Figure 2. The awareness of problem step is concerned with clear definition of the problem and leads to a proposal. The suggestion step deals with proposing possible solution(s) to the problem. The development step involves developing the suggestions into artefacts while the evaluation step is concerned with evaluation of the artefacts. The conclusion stage is the main theory development step and conclusions are drawn tying them to the design knowledge contribution into the existing knowledge base. 
Figure 2: DSR Research process Model

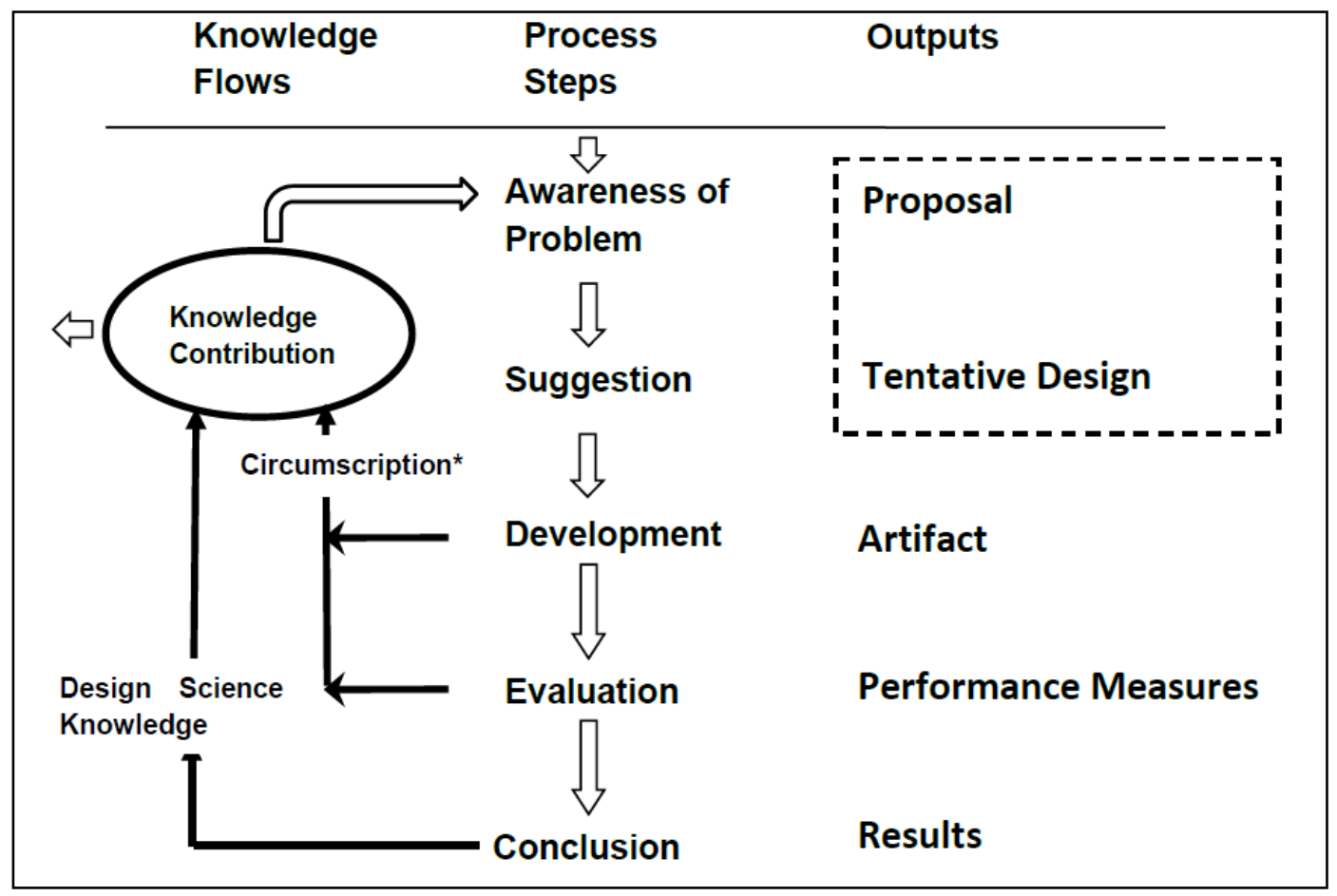

Source: (Kuechler \& Vaishnavi, 2012)

The awareness of problem step refined the research question and the main research question was structured into sub questions as follows: -

What are the factors that must be considered during a HEI website upgrade in order to guarantee continuity of the institution's image and service delivery?

- What are the technical considerations for a HEI website upgrade?

- What are the considerations for HEI image continuity upon website upgrade?

- What are the considerations for continuity of HEI service delivery upon website upgrade?

The suggestion phase was done by taking each of the sub questions and enumerating considerations that must be made resulting in a tentative design. This was done through multiple brainstorming sessions by a focussed group consisting of server administrators, web technology specialists, web administrators and web support teams. The sessions were guided by technological advancements; industry developments; current website features; previous feedback from stakeholders and integration requirements to existing platforms. The tentative design proceeded to development and subsequent evaluation of the first version of a new website which then became the basis for engaging a wider stakeholder community. The wider community consisted of the institution's top management; communication experts; branding professionals; representatives of faculty; student representatives; representatives of persons with disability and representatives from service departments. The engagement of wider community was done through presentations and collecting feedback from different categories of stakeholders, targeted presentations to the different groups to collect feedback on specific aspects and release of a beta version for review. These activities were executed iteratively with reference to relevant theories and practical requirements. After the evaluation phase gave satisfactory results, the main artefact which was an upgraded website was ready for the conclusion phase.

11| This work is licensed under a Creative Commons Attribution 4.0 International License. 
The DSR research approach provides for theory building at different stages of the research process (Kuechler and Vaishnavi, 2012). The framework presented in this research was developed from reflections made at the conclusion phase of the research process. This research resulted in a new website for the case institution as the main artefact addressing the practical problem and this framework is a theoretical contribution to the body of knowledge. The upgrade process was characterised by a lot of trial and error, and the proposed framework provides a structured approach to HEI website upgrade.

\section{RESULTS}

The research identified many aspects that must be managed well during website upgrade in order to ensure a successful upgrade, continuity of services and safeguarding of important image parameters in HEI websites. The research developed four themes the factors could be grouped into: Technology, Usability, Content and Other factors; resulting in the TUCO framework. The factors were logically combined and grouped under the TUCO framework themes, followed by detailed outline of the following framework lenses and upgrade guidelines using the framework. TUCO Framework Components

The framework has four lenses framework namely technical, usability, content and others as shown in Figure 3. Each lens has multiple components and the details are discussed below. The lenses are connected by a hinge which indicates that the upgrade can be viewed independently from each lens and by combining multiple lenses at the same time as necessary.

\section{Figure 3: TUCO Framework components}

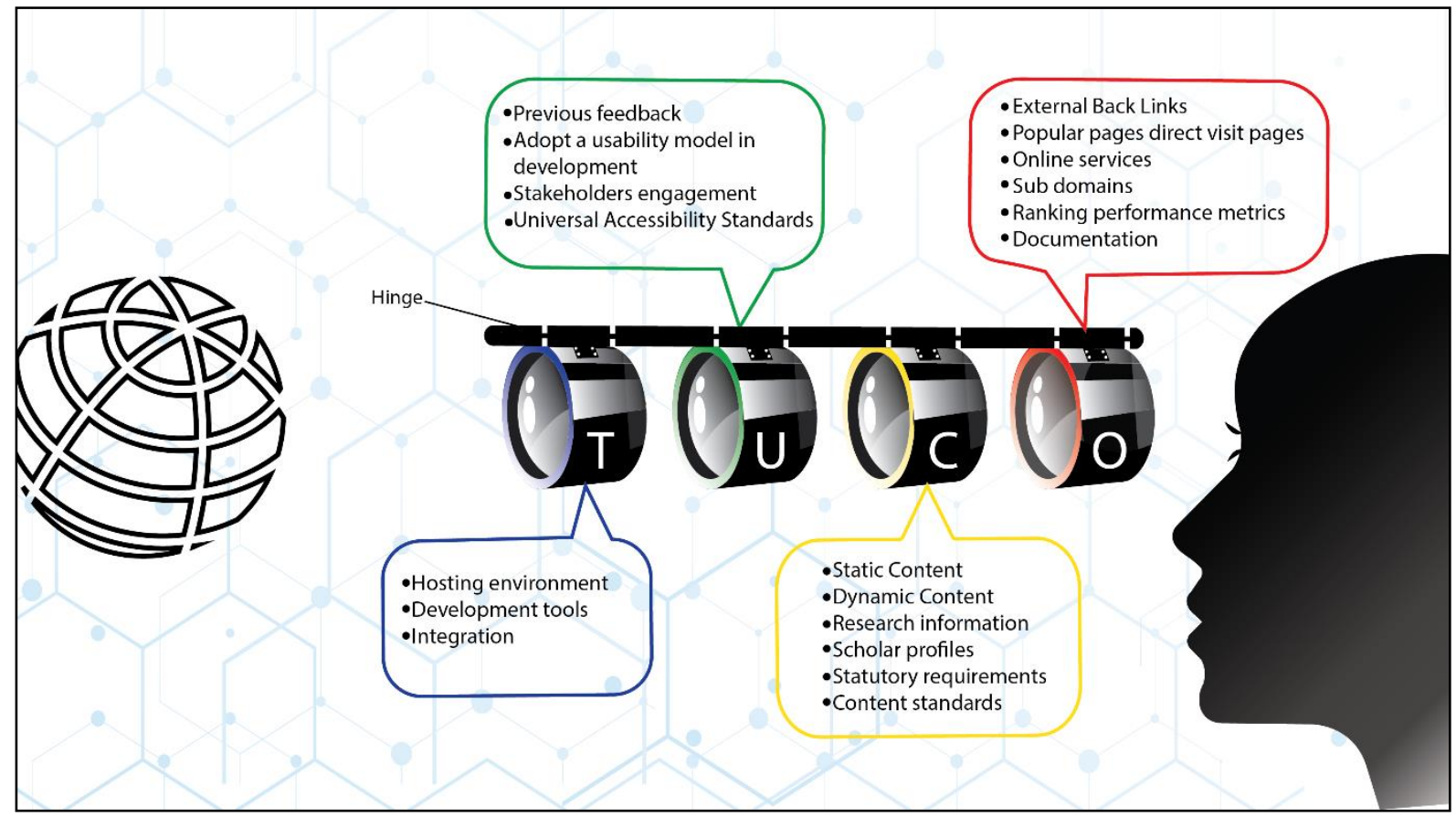

In the sub-sections below, the details of the framework are presented, outlining the components of each of the lenses and the hinge.

\section{Technical}

The technical lens considers the technological considerations that must be made during a website upgrade. Technological advancements emerge frequently, and any website upgrade must ensure optimal technology is used. As a matter of fact, a website undergoes several 'purely technological' upgrades that do not count as website upgrades. These upgrades include upgrades for security reasons, policy compliance and general infrastructural upgrades that in turn upgrade the hosting environment. A deliberate undertaking by a

12| This work is licensed under a Creative Commons Attribution 4.0 International License. 
HEI institution to carry out a website upgrade presents the opportunity to look at the technologies used among other things. This framework proposes a look at the hosting environment, tools used and compatibility with other important systems that exchange data with the website. The three are intertwined and must be considered together with an aim of finding an optimal architecture being the driving factor.

\section{Website Development Tools}

This includes the tools used to develop the website. Tools such as the development framework, scripting language and the database are some of the considerations. Tool selection may include decision on a Content Management System (CMS) to adopt since they have become common for rapid development of websites.

\section{Hosting Environment}

The upgraded website may require an enhanced hosting environment compared to the one hosting the old website. Specification for an ideal environment to host the new website is necessary. The specifications will guide system administrators in creating the environment or can be used in the procurement of an appropriate environment from online clouds if the institution's data centre is not adequate.

\section{Integration}

HEI website may need to be integrated with existing portals for justified reasons. The technical lens must put into perspective the need for such integrations. The integrations may not necessarily need that the integrated systems reside in the same platform but must provide the necessary interfaces for crossplatform integration.

\section{Usability}

The website is a tool for virtual engagement of stakeholders. Usability is therefore an important lens that any upgrade must be viewed from as it is the major determinant of continuity in stakeholder engagement. Majority of the stakeholders would not be interested in the technologies used or other factors, but would only be interested in being able to meet their need in the shortest time possible. To guarantee this dimension, HEI website upgrade must make deliberate considerations on usability including: -

\section{Address Previous Feedback}

Stakeholders often give feedback on a continuous basis during the lifetime of a website. This feedback must be recorded and where possible and within policy must be acted upon immediately. Some of this feedback may require major revision of the website, and an upgrade should prioritize such previous feedback.

\section{Choose A Usability Model to Adopt}

Different models to guide development of usable websites have been developed.

\section{Stakeholder Engagement}

Whichever usability model is adopted, stakeholder engagement must be conducted through constant collection of input during the development of the new website and sensitizations on an upgraded website underway. Stakeholders must be adequately sensitised on the motivations of the upgrade and the centrality of their needs in the website. It is recommended that a beta version of the website is presented to stakeholders before a full roll over. Stakeholder engagement will improve acceptance of the new website once it is launched.

\section{Universal Accessibility Standards}

In the recent past, universal accessibility of websites has gained attention of the research community and the industry at large. Standards for universal accessibility of websites have emerged and are increasingly being adopted by institutions. Website upgrade must ensure that web accessibility standards approved by the institution are adhered to, and where no standard exist, the upgrade should adopt a generic guideline such as the WCAG guideline.

\section{Content}

HEI website content have many commonalities across institutions. The differences are often in the way the content is presented. The Content lens of 
the framework looks at how different categories of content should be treated during an upgrade.

\section{Static Content}

Static content constitutes institutional facts that do not change at all or seldom change. This includes historical facts about the institution and addresses. During an upgrade, this type of content must be migrated and enhanced where necessary. The addresses must be updated and confirmed to be functional.

\section{Dynamic Content}

Dynamic content is that which is generated frequently and have short relevance time frames. This includes contents such as announcements, events, news and alerts. Only the currently active items of this type must be migrated.

\section{Research Information}

Research information is usually documented in the form of publications, research projects, and featured research articles. The publications are usually hosted in the respective journal and if the website provided links to such articles, the same links could be migrated to the new website. Featured research articles must be evaluated and migrated depending on the relevance. The items not migrated must continue to be available in the old archived website. The website policy may also be used to guide on length of time to retain research information on website, and the research content can be migrated as per policy.

\section{Scholar Profiles}

An important strategic resource in HEI institutions is the scholars. Scholar profiles have therefore become a very critical component of HEI websites, and institutions are increasingly showcasing their quality through the calibre of scholars they have. A website upgrade must therefore ensure all scholar profiles are migrated. If the institution has an independent platform for scholar profiles, then the links to those profiles from the website must be migrated.

\section{Statutory Requirements}

Statutory requirements by governments and regulatory agencies on website information are emerging. Some countries require that certain information are displayed all institutional websites. For instance, in Kenya, it is a requirement that all awarded procurement within a fiscal year is published online. A website upgrade must ensure that such statutory requirements are adhered to by migrating the relevant content depending on the regulations governing the institution.

\section{Content Standards}

Upgrade of a website presents an opportunity to develop or review the standards required of the different content types. Migration of content to the new website must ensure that the required standards are enforced. Standards could include content metadata, content size, and display time frames among others.

\section{Other factors}

Over the years, several other factors that determine the continuity of HEI websites have emerged. In this section, such factors are outlines.

\section{External Back Links}

External back links is a website link from an external domain to a specific URL in the website in question. An external URL could be a link from a collaborator to the page consisting a list of collaborators in the HEI website. The new website may not be representing collaborators information the same way as in the old website, but many collaborators could be linking to the same page. These external links will therefore lead to a broken link on the new website. To mitigate this problem, a redirect page can be created, or all stakeholders can be contacted to revise their link to point to new page or recreate the same page in the new website. These kinds of scenarios are common in HEI websites and having a strategy for managing external backlinks during an upgrade is necessary. Tools for checking all the backlinks to your website exist (e.g., AHREF) and the backlinks landing on specific pages and not the domain name must be managed.

14| This work is licensed under a Creative Commons Attribution 4.0 International License. 


\section{Popular Pages Direct Visit Pages}

Certain URLs in a website get directly accessed by many users either because they have memorised the URL or because they have bookmarked it. Examples include the pages with all degree programmes and fees structure. Irrespective of the reason, a mechanism for dealing with such pages during an upgrade must be put in place. Either the same link is created with the same content, a redirect page with link to where the content moved to or automatic redirect scripts must be created. This will ensure continuity of access to information to audience of such popular pages.

\section{Online Services}

HEI websites is like a resource map to many services, some of which are online. Links to online services that existed in the old site must continue to be provided in the upgraded website. The location of the links may change depending on usability considerations, but the links must be provided.

\section{Sub Domains}

HEI institutions are somewhat like many institutions within one institution since they have many independent units. The use of subdomain names to present information for the many units within the institutional domain name is therefore a common practice. The upgrade should ensure that all the subdomains are migrated and the links to the subdomains from the main domain are retained. Change of subdomain names must be discouraged since the history that a subdomain name has gathered over the years will be lost. In the event that a domain name change is inevitable - such as to align with institutional domain name policy - a redirect page on the old domain to the new domain must be put in place. This will ensure continuity for stakeholders who were accustomed to the old domain name.

\section{Ranking Performance Metrics}

Ranking of HEI based on their website information has become a common place. Any website upgrade must therefore consider the impact the upgrade will have on their ranking. Depending on the ranking the institution considers important, measures must be put in place to ensure the ranking of the institution is not affected negatively. The upgrade must consider the ranking parameters and ensure content that determine the parameters are aligned accordingly. As a general guiding principle, the upgrade must ensure the new website is properly indexed and the necessary Search Engine Optimization (SEO) is carried out on the new website.

\section{Documentation}

HEI websites are characterised by multiple participants whose role is to ensure different content in the website are up to date. Website upgrade in most cases changes the way the participants execute their role. Documentation must therefore be developed to guide participants on how to continue playing the role in the newly upgraded website. Documentation is also an important component in ensuring continuity of the website

\section{The Hinge}

The hinge in the framework makes it possible to use different lenses during a website upgrade. The ability to look at the upgrade in close perspective using one lens or a selected combination of the lenses makes it possible to refine upgrades to selected dimensions. It is also worth noting that, an institution may choose to upgrade one aspect of the website and the framework remains relevant even in such instances.

\section{Upgrade guidelines using the framework}

The research developed some guidelines along the different lenses of the framework that can guide in carrying out HEI websites upgrade. The guidelines are summarised in Table 1 below 


\begin{tabular}{|c|c|c|}
\hline Issue & Guideline & Relevance in continuity \\
\hline 1. Technical & & \\
\hline Tools & $\begin{array}{l}\text { - Adopt the latest optimal } \\
\text { technologies } \\
\text { - Consider conversance of } \\
\text { development team }\end{array}$ & $\begin{array}{l}\text { - Latest technologies will guarantee } \\
\text { stability and support for some time } \\
\text { - Development team should be able to use } \\
\text { the tools, thus continuity in support for } \\
\text { development team as well. }\end{array}$ \\
\hline Environment & $\begin{array}{l}\text { - Ensure optimal hosting solution } \\
\text { - Consider cloud hosting if local } \\
\text { infrastructure is not ideal } \\
\text { - Consider accessibility to } \\
\text { stakeholders some of whom are } \\
\text { external and international }\end{array}$ & $\begin{array}{l}\text { - Optimal environment will ensure } \\
\text { adequacy in hosting and accessibility by } \\
\text { stakeholders }\end{array}$ \\
\hline Integration & $\begin{array}{l}\text { - The environment and tools above } \\
\text { must guarantee required integration } \\
\text { with existing systems } \\
\text { - Be open to different integration } \\
\text { models including APIs }\end{array}$ & $\begin{array}{l}\text { - Sustaining integrations ensures } \\
\text { continuity in integrated services } \\
\text { - Continued accuracy of data displayed on } \\
\text { web }\end{array}$ \\
\hline 2. Usability & & \\
\hline Usability & $\begin{array}{l}\text { - Adopt a usability model for website } \\
\text { design } \\
\text { - Engage stakeholders to ensure } \\
\text { improved usability }\end{array}$ & - Enhanced stakeholder engagement \\
\hline 3. Content & & \\
\hline $\begin{array}{l}\text { Static Content } \\
\text { Historical facts } \\
\text { and addresses }\end{array}$ & $\begin{array}{l}\text { - Content should be Migrated and } \\
\text { updated as necessary }\end{array}$ & $\begin{array}{l}\text { - Relevant for continued information } \\
\text { about the institution and addresses }\end{array}$ \\
\hline Dynamic Content & $\begin{array}{l}\text { - Migrate only most recent content } \\
\text { that the stakeholders are still } \\
\text { interested. }\end{array}$ & $\begin{array}{l}\text { - Only recent and relevant content } \\
\text { necessary for continuity }\end{array}$ \\
\hline $\begin{array}{l}\text { Research } \\
\text { information } \\
\text { (Excludes } \\
\text { research } \\
\text { publications and } \\
\text { research projects) }\end{array}$ & $\begin{array}{l}\text { - Featured research information on } \\
\text { highlighted research must be } \\
\text { migrated. The timeframe of the } \\
\text { content can be spelt out in policy. A } \\
\text { period of one years is a reasonable } \\
\text { time frame in majority of websites } \\
\text { - Featured research for active } \\
\text { research must be migrated. } \\
\text { - Journal articles must be maintained } \\
\text { in journal platforms } \\
\text { - Research project portals must also } \\
\text { be maintained }\end{array}$ & $\begin{array}{l}\text { - Research information though dynamic is } \\
\text { not as fast as news and events. } \\
\text { - Research information does not expire but } \\
\text { continue to add to institutional } \\
\text { repositories } \\
\text { - Older research must continue to available } \\
\text { in university research repositories } \\
\text { - Active and up to one year of featured } \\
\text { research information must be migrated } \\
\text { for continuity }\end{array}$ \\
\hline Scholar profiles & - Content should be Migrated & $\begin{array}{l}\text { - Scholars are important resource in HEI. } \\
\text { Their profiles are therefore relevant for } \\
\text { all core business of the institution and } \\
\text { must always be available and up-to-date }\end{array}$ \\
\hline $\begin{array}{l}\text { Statutory } \\
\text { requirements }\end{array}$ & $\begin{array}{l}\text { - Migrate relevant content and ensure } \\
\text { compliance with statutory and } \\
\text { regulatory requirements. }\end{array}$ & $\begin{array}{l}\text { - Continued compliance to regulators } \\
\text { requirements }\end{array}$ \\
\hline
\end{tabular}

16| This work is licensed under a Creative Commons Attribution 4.0 International License. 


$\begin{array}{ll}\text { Issue } & \text { Guideline } \\ \text { Content standards } & \begin{array}{l}\bullet \text { Site must enforce set standards for } \\ \text { different content types }\end{array}\end{array}$

\section{Others}

Externa

Links

Back - Content should be Migrated with the same URL so that links from external sources are not broken

\section{Relevance in continuity}

- Content standards ensure the site is optimized for human and robots access thus ensuring continuity of access to relevant information

- Migrating this content ensures the external links from other sites to the HEI website are not broken thus ensuring continuity in site accessibility from external sources

- Backlinks is a metric used to rank institutions by some ranking methodologies such as webometrics.

\begin{tabular}{ll}
\hline Popular pages & - These are pages that are popularly \\
direct visit pages & visited directly without navigating \\
& $\begin{array}{l}\text { from other pages and must be } \\
\text { migrated. }\end{array}$
\end{tabular}

- A page redirecting users to visit the current page can be created

\begin{tabular}{ll}
\hline Online services & $\begin{array}{l}\text { Links to all online services must be } \\
\text { provided }\end{array}$
\end{tabular}

- Failure to migrate or create a page for redirection to such pages lead to many pages not found visits thus reducing continuity of positive experience from such users provided 


\begin{tabular}{lll} 
Issue & Guideline & Relevance in continuity \\
Documentation & $\bullet$ Ensure the documentation on how to & Inadequate documentation can reduce \\
manage content and services on the & service efficiency thereby leading to \\
new website is ready upon upgrade & reduced user acceptances of the new \\
& website \\
& $\begin{array}{l}\text { Good documentation will ensure } \\
\text { continuity of updates and positive } \\
\text { experience for those responsible. }\end{array}$ \\
\hline
\end{tabular}

\section{DISCUSSION}

Majority of literature on development HEI websites is anchored on two possible assumptions; first is that the websites are created from scratch and second is that every time an upgrade is done, it is treated as a fresh start. This could be attributed to the fact that the strategic importance of HEI websites is a relatively new phenomenon and a lot of considerations have not been made on the importance and the need for the continuity of services, communication and image upon upgrade.

Upgrade of information systems is not new, and several frameworks for ICT, and IS exist in literature. Frameworks and guidelines targeting HEI websites do not exist and yet in many aspects, they are different from information systems and the same frameworks may not apply. This research has proposed to fill this gap with the TUCO framework and guidelines for using it. The framework sets the stage for researchers to interrogate this area which is bound to get complicated as the role of HEI websites continue to evolve. Development and upgrade of HEI websites is often an outsourced service given to IT companies who may not have internalized the HEI priorities. HEI managers can incorporate this framework into contractual obligations during a website upgrade undertaking. Finally, the TUCO framework provides a starting point for practitioners in general who bear the challenge of upgrading HEI websites without industry guidelines.

\section{CONCLUSION}

This study has proposed framework for upgrade of HEI websites aimed at ensuring continuity upon upgrade. The framework has four lenses of Technical, Usability, Content and Others, hence the framework is named TUCO framework. The framework proposes looking at website upgrade from these four lenses in order to achieve an optimal upgrade for service and image continuity. The components of each lens are outlined and provides an in-depth look at the issues that need to be addressed within each lens. The components are however not exhaustive and can be enhanced based on the institution's requirements. In future, more verification of the framework is recommended through its application in the upgrade of another HEI website.

\section{Conflict of interest}

The author declares that there are no conflicts of interest.

\section{Ethical Approval}

All procedures performed in studies involving human participants were in accordance with the ethical standards of the institution and/or national research committee or comparable ethical standards. This article does not contain any studies with animals performed by any of the authors.

\section{REFERENCES}

Aguillo, I. F., Ortega, J. L., \& Fernández, M. (2008). Webometric ranking of world universities: Introduction, methodology, and future developments. Higher education in Europe, 33(2-3), 233-244.

Aguillo, I., Ortega, J., Fernández, M., \& Utrilla, A. (2010). Indicators for a webometric ranking of open access repositories. Scientometrics, 82(3), 477-486.

Mentes, S. A., \& Turan, A. H. (2012). Assessing the usability of university websites: An empirical study on Namik Kemal University. Turkish 
Online Journal of Educational TechnologyTOJET, 11(3), 61-69.

Akgül, Y. (2017, June). The most violated WCAG 1.0 guidelines by the developers of university websites in Turkey. In 2017 12th Iberian Conference on Information Systems and Technologies (CISTI) (pp. 1-7). Ieee.

Akram, M., \& Sulaiman, R. B. (2017). A systematic literature review to determine the web accessibility issues in Saudi Arabian university and government websites for disable people. International Journal of Advanced Computer Science and Applications, 8(6).

Al-Debei, M. M. (2014). The quality and acceptance of websites: an empirical investigation in the context of higher education. International Journal of Business Information Systems, 15(2), 170-188.

Alahmadi, T., \& Drew, S. (2017). Accessibility evaluation of top-ranking university websites in world, Oceania, and Arab categories for home, admission, and course description webpages. Journal of Open, Flexible and Distance Learning, 21(1), 7-24.

Armstrong, J., \& Franklin, T. (2008). A review of current and developing international practice in the use of social networking (Web 2.0) in higher education.

Bernier, J. L., Barchéin, M., Cañas, A., GómezValenzuela, C., \& Merelo, J. J. (2002). The services a university website should offer. Information Society and Education: Monitoring a Revolution. Serie Sociedad de la Educación, 9, 1746-1750.

Caglar, E., \& Mentes, S. A. (2012). The usability of university websites-a study on European University of Lefke. International Journal of Business Information Systems, 11(1), 22-40.

Chow, A. S., Bridges, M., \& Commander, P. (2014). The website design and usability of US academic and public libraries. Reference \& user services quarterly, 53(3), 253-265.

Conole, G., \& Alevizou, P. (2010). A literature review of the use of Web 2.0 tools in Higher
Education. A report commissioned by the Higher Education Academy.

Hevner, A. R. (2007). A three-cycle view of design science research. Scandinavian journal of information systems, 19(2), 4.

Hevner, A., \& Chatterjee, S. (2010). Design science research in information systems. In Design research in information systems (pp. 9-22). Springer, Boston, MA.

Hollinderbäumer, A., Hartz, T., \& Ückert, F. (2013). Education 2.0-How has social media and Web 2.0 been integrated into medical education? A systematical literature review. GMS Zeitschrift für medizinische Ausbildung, 30(1).

Kuechler, W., \& Vaishnavi, V. (2012). A framework for theory development in design science research: multiple perspectives. Journal of the Association for Information systems, 13(6), 3.

Mohammed, A., Garba, A., \& Umar, H. (2016). University library websites in Nigeria: An analysis of content. World Digital Libraries-An international journal, 9(2), 121-130.

Paul, A. Tess. 2013. The role of social media in higher education classes (real and virtual)-A literature review. Computers in Human Behavior, 29(5), A60-A68.

Pierce, K. R. (2005). Usability Review of the Harvard. Edu Web Site. https://works.bepress.com/kenneth_pierce/4/ (accessed 19 March 2020).

19| This work is licensed under a Creative Commons Attribution 4.0 International License. 